\title{
RCT comparing the clinical effectiveness of conventional instructor-facilitated cardiac compression training to technology enhanced training using high-fidelity mannequins-A pilot study
}

\author{
Alison Pighills*1,2, Rachel Waye ${ }^{1,3}$, Stephanie Taylor ${ }^{3}$, Vicki Braithwaite ${ }^{3}$, Daniel Lindsay ${ }^{4}$, Mohamad Alshurafa ${ }^{1}$ \\ ${ }^{1}$ Mackay Institute of Research and Innovation, Mackay Hospital and Health Service, Mackay, Queensland, Australia \\ ${ }^{2}$ College of Healthcare Services, Division of Tropical Health and Medicine, James Cook University, Townsville, Queensland, \\ Australia \\ ${ }^{3}$ Education and Training Department, Mackay Hospital and Health Service, Mackay, Queensland, Australia \\ ${ }^{4}$ College of Public Health, Medical and Veterinary Sciences, Division of Tropical Health and Medicine, James Cook University, \\ Townsville, Queensland, Australia
}

Received: February 7, 2021

DOI: $10.5430 /$ jnep.v11n8p69
Accepted: April 7, 2021

Online Published: April 20, 2021

\begin{abstract}
Introduction: Healthcare professionals often provide substandard chest compression following cardiac arrest. This is deemed a preventable harm because this skill can be acquired. The recent development of technology-enhanced cardiac compression training devices provides an alternative to traditional instructor-facilitated training. This pilot study compared the effectiveness of conventional and technology-enhanced training modalities.

Methods: A pilot randomised controlled trial design was used in a regional hospital in Queensland. Following baseline assessment, healthcare staff were randomised to one of three groups: traditional instructor-facilitated training; high-fidelity mannequin training and continuous access to the training system to practise skills; and, high-fidelity mannequin training with no further access to the training system to practise skills. The primary outcome, cardiac compression skill levels, was analysed using analysis of co-variance, adjusting for predictive co-variates. Secondary measures were analysed using inferential statistics or presented descriptively.

Results: Between January and February 2017, 502 healthcare staff were recruited. At baseline, $21 \%$ were competent in cardiac compression, increasing to $38 \%$ on reassessment. The mode of training did not affect skill level $(\mathrm{F}(92,392)=0.061, p=.94)$, however, participants in the high-fidelity mannequin training group who practised their skills had statistically significantly higher reassessment scores $(\mathrm{z}=-2.34, p=.019)$. Baseline score and the number of times participants practised their skills were significant predictors of reassessment scores $(\mathrm{F}(2,392)=7.73, p=.001)$.

Conclusions: Most hospital staff who may need to perform cardiac compression were not competent in this skill. Neither training modality was more effective. Both training and practise increased cardiac compression skill levels, indicating that frequent, low-dose training is required.
\end{abstract}

Key Words: Cardiac arrest, Cardiac compression, CPR, Patient safety, Education, Simulation

*Correspondence: Alison Pighills; Email: alison.pighills@ health.qld.gov.au; Address: Mackay Institute of Research and Innovation, Mackay Base Hospital, P.O. Box 5580, Mackay Mail Centre, Mackay, Queensland 4741, Australia. 


\section{INTRODUCTION}

The quality of chest compressions provided by healthcare professionals and trained rescuers is notoriously poor. ${ }^{[1-5]}$ Although, the positive relationship between effective chest compressions, survival and favourable neurological outcome is well established, ${ }^{[3,6-10]}$ research suggests that compression depths are suboptimal for almost all patients. ${ }^{[1,3,11]}$ Effective chest compressions are the foundation for downstream resuscitation efforts and significantly positively influence outcome. ${ }^{[3,12]}$ To provide the best chance of return of spontaneous circulation (ROSC) adult chest compressions should be delivered at a rate of $100-120 / \mathrm{min}$, to a depth of at least $50 \mathrm{~mm}$, with release to allow complete chest wall recoil and minimal interruption to compression. ${ }^{[7,12]}$ Substandard chest compression is deemed a preventable harm because effective cardiopulmonary resuscitation can be taught and skills acquired. ${ }^{[6]}$

Chest compression knowledge is described as knowing and performing the correct actions sequence, and skill is defined as using the correct rate, depth and hand position. ${ }^{[13]}$ Real time objective measurement and feedback significantly improve the quality of chest compression skill and effective skills training increases survival rates following cardiac arrest. $^{[9,14-17]}$

Annual recertification of cardiac compression skill is mandatory for most healthcare organisations, as recommended by international resuscitation councils..$^{[5,7,18]}$ The provision of cardiac compression training is generally through annual instructor-facilitated training with subjective assessment of participants, which usually takes approximately an hour, however, guidelines suggest that retraining cycles of 1-2 years are insufficient to maintain competence. ${ }^{[5,18]}$ A number of issues have been identified regarding training of acute health care staff in compression skills, including: recommended retraining timeframes; the logistical management and resourcing of training; objectively measuring effectiveness in staff capability; and, the cost of retraining cycles ${ }^{[5]}$ Compliance with retraining regimens is also variable and often poor.

Skills retention following cardiac compression training significantly declines over the first two to six months, ${ }^{[5,13,19,20]}$ with less than $50 \%$ of trainees remaining proficient at five months. ${ }^{[21]}$ Skills decay rapidly after initial training, ${ }^{[7,19,22]}$ and 1-2 yearly retraining cycles do not maintain competence in compression skills. ${ }^{[7]}$ Compression skills are further affected by the urgency and emotive circumstances of the resuscitation situation and lack of regular exposure to real life events in human patients. ${ }^{[5]}$ International consensus is to provide high frequency, low dose cardiac compression training, to prevent skill degradation, using mannequins which provide directive feedback (high-fidelity mannequins) to enhance skill acquisition, as trainers are unable to reliably identify sub-optimal compressions, thus, are unable to provide consistent corrective feedback. ${ }^{[7,23]}$

Advances in simulation technology have led to the development of technology-enhanced cardiac compression training devices. High-fidelity mannequins incorporate the latest in computer technology into a realistic-looking full body which provides comprehensive feedback to the trainee. These mannequins provide objective, real time, audio-visual feedback on compression rate, depth, release and hand position during assessment and have been shown to be more effective than instructor-facilitated training and subjective assessment, undertaken by assessors. ${ }^{[4,14,20,24,25]}$ Research reveals that high-fidelity mannequins enhance trainees' ability to provide high quality continuous chest compressions of appropriate rate and depth. ${ }^{[3,5,9,20,26,27]}$ One such device is the American Heart Association Resuscitation Quality Improvement (RQI) training system (Laerdel Pty Ltd.), which is purported to: provide objective measurement of cardiac compression skills and record training compliance rates; enable healthcare providers to embed high-quality cardiac compression performance, through annual learning modules and quarterly self-directed 10-minute drills; and, be more cost effective compared to conventional instructor-facilitated training and e-Learning methods. ${ }^{[24]}$ Use of high-fidelity simulation has a positive effect on skill acquisition and retention. ${ }^{[19,26]}$

This pilot study evaluated the difference in staff cardiac compression skill levels between a group who underwent training using a high-fidelity mannequin via the RQI training system and a control group who underwent the traditional instructorfacilitated training provided by the Hospital and Health Service. We additionally examined skill levels between different disciplines.

Our research questions were:

1) Is technology enhanced cardiac compression training more effective in improving skills, as compared to conventional instructor-facilitated cardiac compression training, for health care staff who may have to perform cardiac compression as part of their role?

2) Does practising cardiac compression skills between assessments increase skill level as compared to no skills practise? 3) At what timepoint post training do cardiac compression skills decline?

4) Were cardiac compression skill levels different between disciplines, at baseline and on re-assessment?

This study has several unique aspects. Evaluating time to skills degredation has been identified as an important research focus to determine whether brief booster training 
sessions are sufficient for skill retention over time. ${ }^{[28]}$ There is a paucity of research assessing skill retention over a longer follow-up period. Finally, few studies have evaluated the clinical effectiveness of different training modalities in a realistic clinical setting, and few have taken place in a regional, as opposed to a municipal, location.

\section{MethodS}

A three-group randomised controlled trial (RCT) was carried out in a regional hospital in Queensland, Australia and received ethics approval from Townsville Human Research Ethics Committee (HREC/16/QTHS/82). ACTRN:ACTRN12620000434998.

The trial comprised of a control group who received usual instructor-facilitated training via mannequins incorporating either no feedback or low-fidelity visual feedback mechanisms (group A - traditional training); an intervention group who were trained using the RQI training system and had continuous access to the system to practice their cardiac compression skills throughout the trial (group B - RQI continuous access), to replicate how the system is intended to be used; and, an intervention group who were trained using the RQI training system but had no other interaction with the system throughout the trial (group C - RQI one off access), to mimic group A's inability to practise skills.

The pilot study was divided into two elements as follows:

\section{Element 1: Effectiveness of cardiac compression train- ing and skill retention}

The difference in health care staff competence in performing cardiac compression was measured between the control group, which underwent traditional instructor-facilitated training, and the two intervention groups, which received skills training and objective feedback via the RQI training system and had continuous access to the system to practise skills (group B) or one off access for training purposes only (group C). The difference in competence in performing cardiac compression was also measured between doctors, nurses, health practitioners and operational officers. Staff cardiac compression skill levels were measured over various timepoints, to elicit the timeframe over which staff maintained competence.

\section{Element 2: Intensity of skills practice}

The difference in staff competence in performing cardiac compression with differing levels of skills practice was measured between groups. This was achieved by reviewing the number of times each group B participant accessed the RQI training system to practice cardiac compression skills outside of the baseline and reassessment timepoints.
Health care staff were eligible to be included in the study if they: were medical, nursing, allied health or identified operational staff who may be required to provide cardio-pulmonary resuscitation as part of their role; were permanent or temporary employees, with contracts ending after the study end point; worked in any unit in the regional Hospital; and, were over 18 years of age. Staff were excluded if they: were planning extended leave during the study period; were on a modified return to work program that excluded them from performing cardiac compression; or, were unable to perform cardiac compression due to pregnancy, injury or ill health.

The primary outcome measure was the level of competence in cardiac compression (\% score at baseline, three and sixmonth follow up assessments). This was measured by the RQI training system which provided an objective, composite measure of compression rate, depth, release and hand position, summarised as a percentage skill score, with $\geq$ $75 \%$ indicating a successful resuscitation attempt. Secondary measures included the proportion of people who passed the objective assessment on the RQI training system (75\% or over), time to skill degradation and the number of times staff in group B practised cardiac compression skills.

We determined that a $20 \%$ difference between group mean competency scores would be highly clinically significant. To detect a difference of 0.2 between the experimental and control group means with 0.9 power, we calculated that we would need to study 132 subjects in each group (equating to 396 participants) to be able to reject the null hypothesis, that the population means of the experimental and control groups are equal. The Type I error probability associated with this test of the null hypothesis was 0.05 . Allowing for $20 \%$ attrition, in anticipation of high staff turnover, we aimed to recruit 475 participants.

Recruitment took place from 16th January to the 28th February 2017. Staff were recruited by electronic invitation, researchers visiting clinical areas and inviting staff to participate, word of mouth and opportunistic recruitment. Potential participants were given a participant information sheet and asked to complete and return a consent form. Once participants had provided informed consent, a baseline assessment of cardiac compression skill was carried out.

Baseline, three and six-month follow-up assessments of cardiac compression skill level were carried out with all three groups, using the RQI training system. Study participants were blinded to the outcome of the baseline and follow-up assessments. Feedback components were deactivated or could not be seen or heard by the participants, so that participants were unaware of their individual results, which were stored electronically on the RQI training system. In addition, out- 
come assessors and the statistician were blinded to group allocation, but it was not possible to blind participants.

At the baseline assessment, the participant's employee identification (ID) number and group allocation were entered into the RQI training system to enable group A and C participants to be deactivated until their reassessment. This was to prevent them from accessing the RQI training system to practise cardiac compression skills between assessments. Group B had access to the RQI training system to practise cardiac compression skills throughout their participation in the trial.

Participants were randomised in blocks of 12 within each discipline (medical, nursing, allied health, operational) to the three groups, to equally distribute participant numbers for each discipline between groups. A computer-generated randomisation code was created, using simple web-based randomisation, and participants were randomised in the order that they attended for baseline assessment within each discipline.

The control group (A) was trained in cardiac compression skills via instructor-facilitated training, which lasted approximately 15 mins. This involved training in Basic Life Support (BLS), including instruction on compression and defibrillation techniques and assessment of BLS skills through observation of performance using mannequins, incorporating either no feedback or low-fidelity visual feedback mechanisms. Trainers ensured that participants achieved skill levels consistent with a pass before completing their training session.

Groups B and C were trained in cardiac compression skills via the RQI training system with standardised instructions for recommended use. Once logged onto the system they: watched a video recording demonstrating the correct cardiac compression technique; carried out compressions on the mannequin whilst receiving visual and auditory feedback on their technique in relation to compression rate, depth, release and hand position; and, completed scenarios.

Staff were able to complete the cardiac compression training on the RQI training system independently, however, most required trainers to show them how to access and navigate the system. This enabled the trainers to ensure that participants achieved a pass (cardiac compression skill score of $\geq 75 \%$ ) before they ceased their training session.

Weekly reports were generated from the RQI training system database providing the staff ID of participants who had accessed the system for initial training, reassessments or skills practise. These reports were screened to determine whether any staff in groups $\mathrm{A}$ and $\mathrm{C}$ had accessed the system to practise their compression skills so that this variable could be included in the analysis. To ensure data integrity, scores for every baseline and follow-up assessment were recorded on a spreadsheet and cross checked with the RQI system output. Regular reminders were emailed to participants to complete their training and undergo reassessments, outlining reassessment due dates.

\section{Analysis methods}

Descriptive statistics summarised recruitment, attrition and combined averages for all cardiac compression attempts and best cardiac compression attempts. The primary outcome was cardiac compression skill level. We carried out a multiple-regression analysis, in the form of analysis of covariance, to adjust for predictive co-variates, which included baseline competence scores and the number of times group B participants (continuous access to the RQI training system) practised their compression skills.

Secondary measures included: the difference in baseline and reassessment cardiac compression scores based on job type, analysed using a mixed factorial analysis of variance; the difference between disciplines in their level of competence in cardiac compression over time, analysed using Chi-square; predictors of reassessment scores, analysed via multiple linear regression; the association between reassessment score and the number of times the RQI training system was accessed to practise skills, analysed via Spearman's correlation coefficient; and, the difference in re-assessment scores between the three groups and an unplanned control group who did not receive any training, analysed via the Kruskal-Wallis test.

A survival analysis was carried out to identify the timepoint post training when cardiac compression skills declined. In the absence of data to judge what a clinically significant decline in cardiac compression skills would be, we took a decline of $\geq 10 \%$ in score from baseline to reassessment, as the indicator of a decline in cardiac compression skills, to determine whether "the event" had taken place. Significance tests were 2 -sided at the 5\% level for both primary and secondary outcomes.

\section{Results}

Recruitment exceeded the target of 475 with 502 participants recruited during January and February 2017. We required baseline and follow-up data for 132 participants in each of the three arms of the trial and achieved 132 in the control group (group A), 133 in the continuous access to the RQI training system (group B) and 128 in the one-off access to the RQI training system (group C). Three hundred and ninety-three participants provided baseline and follow-up data reflecting a $22 \%$ attrition rate. Attrition did not appear to be related to 
the study outcome, with $83 \%$ of attrition due to staff leaving the organisation, moving to another facility, taking extended leave or being unable to perform cardiac compression due to physical limitations and only $17 \%$ being unexplained or due to workload pressure. Despite the high attrition rate, partici- pants lost to follow-up had similar baseline characteristics to those retained in the study and the cause of attrition was likely random (staff turnover). Figure 1 shows participant flow through the study including reasons for attrition of 109 participants (see Figure 1).
Baseline assessment

Follow-up assessment

Trial completion

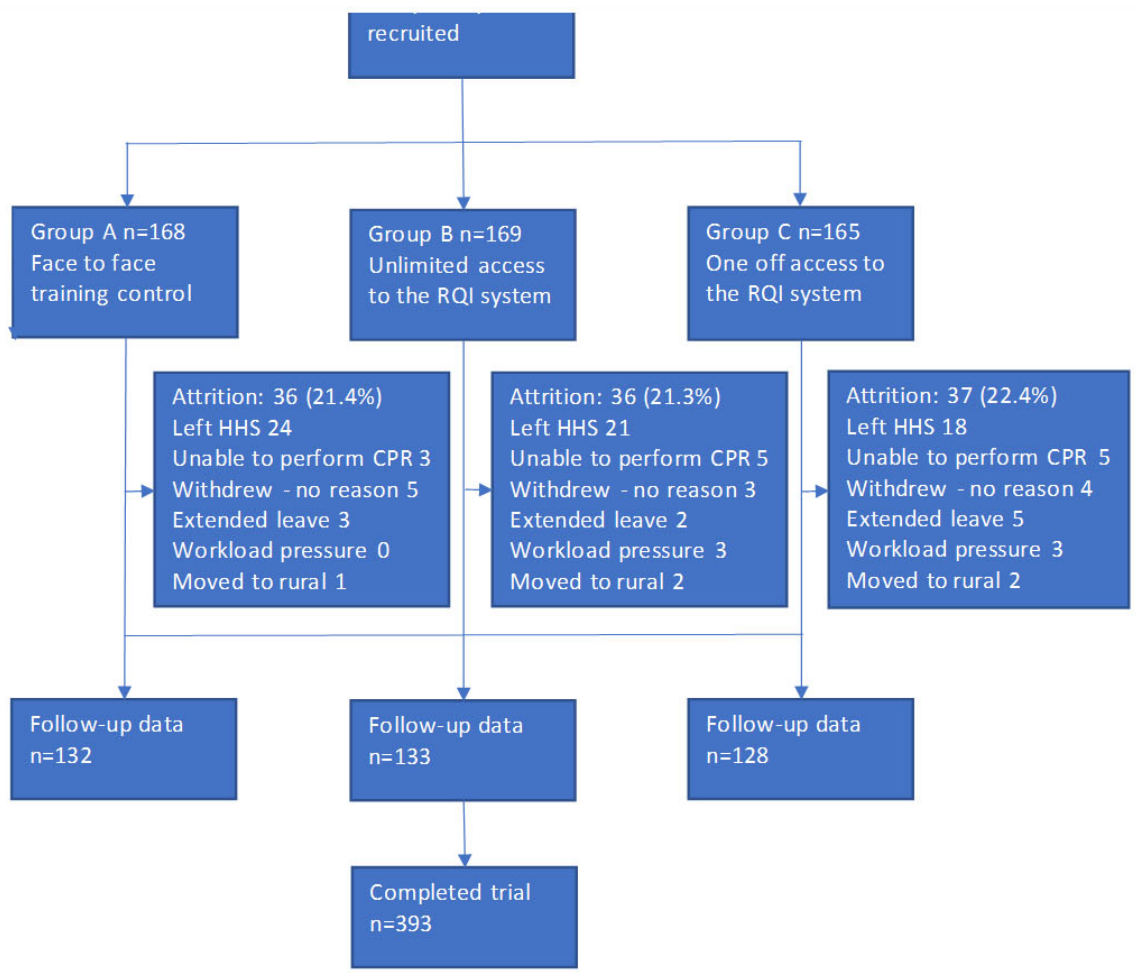

Figure 1. Participant flow through the study

Attrition was equally distributed between groups (see Figure 1). In total, $21 \%$ of doctors; $25 \%$ of nurses; $20 \%$ health practitioners, and; $11 \%$ of operational staff were lost to follow-up. Of those lost to follow-up $68 \%$ did not receive any training via the study.
At baseline, only $21 \%$ of staff passed the blinded cardiac compression assessment (see Table 1). A Chi-square analyses revealed a significant association between disciplines and performance on the cardiac compression assessment $\left(\chi^{2}(3)\right.$ $=12, p=.007$ ).

Table 1. Participant baseline characteristics by group

\begin{tabular}{llll}
\hline Characteristic & $\begin{array}{l}\text { Group A } \\
\text { control } \\
\text { (n= 168) }\end{array}$ & $\begin{array}{l}\text { Group B } \\
\text { continuous } \\
\text { (n= 169) }\end{array}$ & $\begin{array}{l}\text { Group C } \\
\text { one off } \\
\text { (n = 165) }\end{array}$ \\
\hline Discipline group - Number (\%) & & & \\
Doctor & $29(17)$ & $31(18)$ & $28(17)$ \\
Nurse & $92(55)$ & $90(53)$ & $91(55)$ \\
Health Practitioner & $26(16)$ & $25(15)$ & $24(15)$ \\
Operational Officer & $21(13)$ & $23(14)$ & $22(13)$ \\
Mean baseline CPR score - Mean (SD) & $38(34)$ & $36(35)$ & $38(34)$ \\
Passed baseline cardiac compression assessment - Number (\%) & $40(24)$ & $34(20)$ & $31(19)$ \\
Median days from previous training to baseline assessment - Number (IQR) & $205(209)$ & $185(259)$ & $188(216)$ \\
Attrition - Number (\%) & $36(21)$ & $36(21)$ & $37(22)$ \\
\hline
\end{tabular}


The baseline assessment of cardiac compression skills was passed by $33 \%$ of the 88 doctors in the study; $17 \%$ of the 273 nurses; $16 \%$ of the 75 health practitioners; and, $26 \%$ of the 66 operational officers. Doctors had a significantly higher rate of passing their assessment than nurses $\left(\chi^{2}(1)=9.92\right.$, $p=.002)$, and health practitioners $\left(\chi^{2}(1)=6.18, p=.013\right)$, but not operational officers $(p>.05)$. No other significant differences based on discipline were found (see Table 2).

Table 2. Participant characteristics by discipline stream

\begin{tabular}{lllll}
\hline Characteristic & $\begin{array}{l}\text { Doctors } \\
\mathbf{n = 8 8}\end{array}$ & $\begin{array}{l}\text { Nurses } \\
\mathbf{n = 2 7 3}\end{array}$ & $\begin{array}{l}\text { Health Practitioners } \\
\mathbf{n}=\mathbf{7 5}\end{array}$ & $\begin{array}{l}\text { Operational } \\
\text { Officers } \mathbf{n}=\mathbf{6 6}\end{array}$ \\
\hline $\begin{array}{l}\text { Median days from previous training to baseline } \\
\text { assessment - Number (IQR) }\end{array}$ & $229(230)$ & $183(184)$ & $206(289)$ & $201(250)$ \\
$\begin{array}{l}\text { Passed baseline cardiac compression assessment - } \\
\text { Number (\%) }\end{array}$ & $29(33)$ & $47(17)$ & $12(16)$ & $17(26)$ \\
$\begin{array}{l}\text { Passed follow-up assessment - Number (\%) } \\
\text { Attrition - Number (\%) }\end{array}$ & $33(47)$ & $70(34)$ & $28(47)$ & $19(32)$ \\
Completed the trial - Number (\%) & $70(21)$ & $69(25)$ & $15(20)$ & $7(11)$ \\
\hline
\end{tabular}

On reassessment, $38 \%$ of staff passed the blinded cardiac compression assessment. There was no statistically significant association between disciplines and performance on reassessment $\left(\chi^{2}(3)=6.40, p=.094\right)$. Of the staff who completed the reassessment, $47 \%$ of the 70 doctors; $34 \%$ of the 204 nurses; $47 \%$ of the 60 health practitioners; and, $32 \%$ of the 59 operational officers passed the blinded reassessment (see Table 2).

There was no significant difference in the proportion of doctors or operational officers passing the baseline compared to the reassessment $\left(\chi^{2}(1)=3.23, p=.07 ; \chi^{2}(1)=0.61, p\right.$ $=.43$ respectively). There was a significant difference in the proportion of nurses and health practitioners passing the baseline compared to the reassessment $\left(\chi^{2}(1)=18.41, \mathrm{p}<\right.$ $.0001 ; \chi^{2}(1)=14.95, p<.0001$ respectively).
A 2 × 4 mixed factorial analysis compared the difference in baseline and reassessment cardiac compression scores based on job type. There was a significant main effect for assessment timepoint (baseline or reassessment) $(\mathrm{F}(1,389)=21.97$, $p<.001)$, and for job type $(\mathrm{F}(1,389)=3.81, p=.01)$, with no significant interaction $(\mathrm{F}(3,389)=1.36, p=.26)$. Independent of assessment timepoint, doctors scored significantly more highly on the cardiac compression assessments than nurses $(p=.005)$. No other significant differences based on job type were found. Independent of job type, participants scored significantly more highly on their reassessment than they did at baseline $(p<.001)$ (see Table 3 for descriptive statistics for this analysis). This analysis shows that all groups improved over time, regardless of job type.

Table 3. Estimated Marginal Means (SE) for cardiac compression scores based on timepoint and job type

\begin{tabular}{lll}
\hline Variable & & $\begin{array}{l}\text { Mean (SD) cardiac compression scores averaged for baseline and } \\
\text { reassessment timepoints within discipline groups }\end{array}$ \\
\hline \multirow{2}{*}{ Job Type } & Doctor & $54.45(3.24)$ \\
& Nurse & $41.83(1.90)$ \\
& Health practitioner & $44.85(3.50)$ \\
& Operational officers & $43.82(3.53)$ \\
\hline \multirow{2}{*}{ Variable } & & Mean (SD) cardiac compression score averaged across all discipline \\
& & groups for baseline and reassessment timepoints \\
Assessment & Baseline & $40(1.98)$ \\
\hline
\end{tabular}

Figures 2 and 3 summarise the combined averages for all cardiac compression attempts and best cardiac compression attempts respectively for all participants in the trial collectively. These figures show that compression attempts failed based on compression rate followed by compression depth, which were the parameters with the lowest scores. Hand position and release (recoil) achieved the highest scores and were both above the $75 \%$ pass mark. 


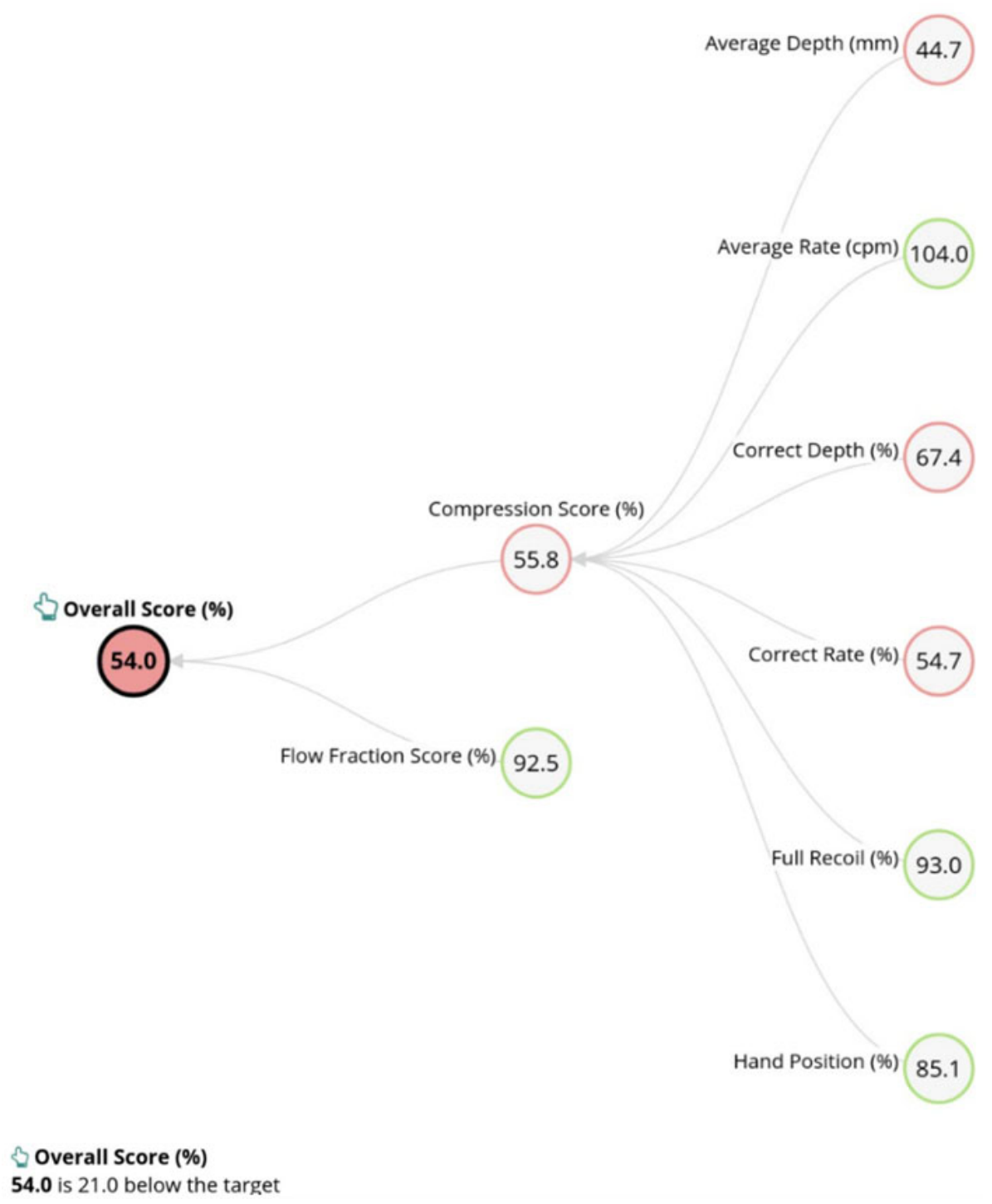

Figure 2. Combined averages for all cardiac compression attempts

We intended to carry out the first reassessment of cardiac compression skill level at three months post cardiac compression training, however, despite several participant reminders, the first reassessment took place at a variety of timepoints post training (median 133 days, IQR 68). In addition, only 20 participants attended for a second reassessment of skill level, which was scheduled for 6 months post baseline assessment (group B $n=19$; group A $n=1$ ). Therefore, results for the second reassessment were not analysed.

After controlling for baseline score and the number of times group B participants practised their cardiac compression skills on the RQI training system, there was no statistically significant difference between groups in mean cardiac com- pression score on reassessment $(\mathrm{F}(2,392)=0.061, p=.94)$, indicating that the mode of training delivery did not affect skill level. A multiple linear regression showed that baseline cardiac compression score $(\beta=0.171, p=.001)$ and the number of times participants practised their skills $(\beta=$ $0.105, p=.001$ ) were both significant predictors of reassessment cardiac compression scores $(\mathrm{F}(2,392)=7.73, p=.001)$, with higher baseline scores and a greater number of times practising cardiac compression skills improving overall reassessment performance.

Only 57\% of participants in group B practised their cardiac compression skills between assessments. Statistically significantly higher reassessment scores were achieved by those 
participants in group B who practised their skills on the RQI training system (median 61, IQR 72) than those in the other groups combined, including group B participants who didn't practice, (median 46, IQR 76, z = -2.34, $p=.019$ ).

In Target $\bigcirc$ Outside Target $O$

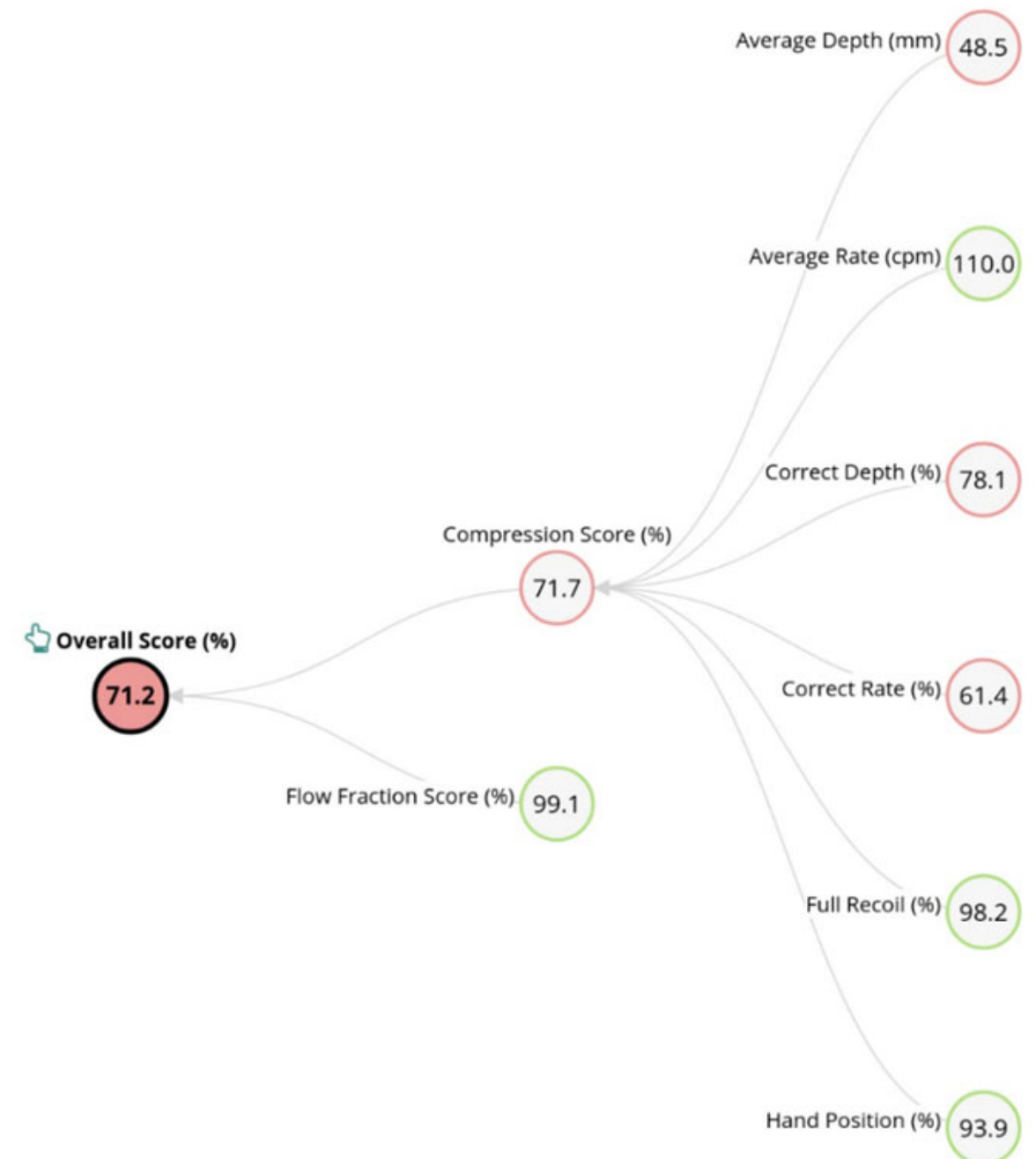

\section{Overall Score (\%)}

71.2 is 3.8 below the target

range.

Figure 3. Combined averages for best cardiac compression attempts

There was no correlation between baseline score and number of times participants in group B, who had continuous access to the RQI training system, practised their cardiac compression skills ( $\mathrm{rho}=.032, p=.240$ ), indicating that staff were unaware of their skills deficit.

Only $64 \%$ of all participants in the study attended training in cardiac compression skills ( $73 \%$ of those who provided follow-up data), even though this training is mandatory, and participants agreed to undertake ether instructor-facilitated or RQI based training on signing up to the study. In addition, there was wide variation in the time from baseline assessment to when participants attended training (median 161, IQR 114). Reassessment scores were statistically significantly higher for those who attended training (median 58, IQR 69) than for those who did not (median 32, IQR 76, z = $-3.14, p=.002)$.

The participants who did not receive any training formed an unplanned control group. When reassessment scores were 
compared for participants in the 3 intervention groups who received cardiac compression training and a control group of participants who did not using the Kruskal-Wallis test, there was a statistically significant difference between the four groups $\left(\chi^{2}(3)=11.30, p=.01\right)$, indicating that training improved performance. Participants in group B (RQI continuous access) had significantly higher median scores on reassessment than those in the unplanned control group, $p=.002$ (see Table 4). No other statistically significant differences were found.

Table 4. Reassessment results for the three groups including the unplanned no intervention control group, excluding those lost to follow-up

\begin{tabular}{ll}
\hline Group & $\begin{array}{l}\text { Median (IQR) } \\
\text { reassessment score }\end{array}$ \\
\hline No training - unplanned control $(\mathrm{n}=107)$ & $32(76)$ \\
Group A - instructor-facilitated training $(\mathrm{n}=104)$ & $53.5(68)$ \\
Group B - RQI continuous access $(\mathrm{n}=99)$ & $64(80)$ \\
Group C - RQI one-off access $(\mathrm{n}=83)$ & $58(70)$ \\
\hline
\end{tabular}

Survival analysis revealed that there was no statistically significant difference between groups in time to a $10 \%$ decline in cardiac compression skill score from training to reassessment $\left(\chi^{2}=0.095, p=.954\right)$ and that the median time to a $10 \%$ decline in mean score was 245 days (approximately 8 months) (95\% CI 227-263).

There was a statistically significant negative correlation between time from training to reassessment and reassessment mean score $(r=-.142, p=.016)$ reinforcing that reassessment scores decreased as time from training to reassessment increased. This result should be interpreted cautiously due to the low $r$ value.

Baseline and reassessments were blinded; thus, participants were only made aware of their score after their reassessment. Upon discovering their final score, many participants opted to practise their cardiac compression skills immediately post reassessment. There was a statistically significant negative correlation between the reassessment score and the number of times participants practised immediately after the reassessment (correlation coefficient $-0.114, p=.024$ ), indicating that the lower the score the more times participants practised their skills, although the $\mathrm{r}$ value is low.

\section{Discussion}

At baseline only 1 in 5 staff were competent in cardiac compression, increasing to 1 in 3 on reassessment. Baseline scores were $15 \%$ lower than that found in a paediatric study, ${ }^{[28]}$ and consistent with other research which found cardiac compression skills to be suboptimal in all study groups. ${ }^{[2]}$ Indeed, cardiac compression skills have previously been found to be highly variable in the hospital setting. ${ }^{[11]}$ Of note, medical and operational staff had the highest mean scores at baseline, possibly because they are the disciplines who tend to do the hands-on chest compressions when required in hospital.

Although, cardiac compression training increased healthcare staff skill levels, neither training modality was significantly more effective than the other. These findings reflect some previous studies, ${ }^{[2,28]}$ although, the majority of research, ${ }^{[5,9,24]}$ including systematic reviews, ${ }^{[29]}$ has found automated cardiac compression training to be superior to instructor-facilitated training. Indeed, when Group B participants practised between assessments on the RQI training system, as intended, their skill scores were statistically significantly higher than those of the other groups combined. However, these scores were not clinically significant because the median ( $61 \%$ vs $46 \%$ ) was still below the $75 \%$ cut off, indicating a successful resuscitation attempt.

There appeared to be a lack of self-awareness of cardiac compression skill deficits, possibly due to a lack of bio-feedback during the assessments. Participants in the control group didn't receive bio-feedback during instructor-facilitated training and those in the RQI training system groups, who didn't access the system to practise their skills, were unaware of their actual, as opposed to perceived, skill level. Indeed, many participants only practised cardiac compression skills when they received feedback on their score post final reassessment and realised that their competence level was lower than perceived. Indeed, other research has found that medical staff reported a perception of high efficacy in cardio-pulmonary resuscitation, which didn't correspond with high skill levels. ${ }^{[30]}$ This demonstrates the influence of feedback on behaviour and highlights the need for change management processes, and possibly enticements, to encourage staff to practise cardiac compression skills.

Cardiac compression skill levels declined equally between groups at around eight months post training. Conversely, other studies have found that skill retention was significantly higher in the groups trained using high-fidelity mannequins, as opposed to instructor-facilitated training, and that skills significantly declined as early as five months post training. ${ }^{[9,31]}$ To this end, three-monthly skills retraining cycles are advocated, ${ }^{[19,32]}$ as skills decline more quickly than knowledge. ${ }^{[13]}$

Of note, $36 \%$ of staff did not attend any cardiac compression training during the study ( $42 \%$ of doctors; $40 \%$ of nurses; $24 \%$ of operational; and, $24 \%$ of health practitioner staff), even though training is mandatory, and staff enrolled in the study agreed to attend training. The staff groups with the 
lowest training participation rates were most likely to be involved in a real-life cardio-pulmonary resuscitation event. When groups were analysed, based on whether they attended training, results showed a statistically significant difference between the group which attended training and the group which did not, with the RQI continuous access group (B) achieving the highest median score. This reflects the effectiveness of training in increasing cardiac compression skill levels. ${ }^{[23]}$ Indeed, operational and health practitioner staff had the highest training attendance rates $(76 \%)$ and showed the greatest improvement in mean cardiac compression score between baseline and reassessment. The number of staff attending training may reflect the effectiveness of management processes within staff groups.

\subsection{Pilot Learnings}

\subsubsection{Training}

This pilot study afforded several learnings for a future definitive trial. The median timeframe from baseline assessment to training was 161 days (IQR 114). Providing training at the point of recruitment would have removed this variability and ensured that all participants enrolled in the study received training. We anticipated that staff would be able to follow written and on-screen instructions to undertake independent training on the RQI system, however, in practice, assessors helped most participants in groups $\mathrm{B}$ and $\mathrm{C}$ to navigate the $\mathrm{RQI}$ training system. This was probably due to unfamiliarity with, and counter intuitiveness of, the system and/or limited time to work out how to navigate it. This was unanticipated and time consuming for study team members, although it enabled them to ensure that staff didn't abort training until they had achieved the required skill level (pass score 75\%+). Some participants did their training independently and received audio and visual feedback on performance. Upon recruitment, it would have been beneficial to give participants in group B instruction on how to use the RQI training system and information on where the systems would be located for ease of access for skills practise.

Group A was trained using no feedback or low-fidelity mannequins, therefore, groups $\mathrm{B}$ and $\mathrm{C}$ may have had some advantage by being trained on the high-fidelity mannequins that were used for the re-assessments.

A blinded assessment of skill acquisition immediately post training was not carried out, as has happened in other studies. ${ }^{[19]}$ This would have provided a benchmark of post training skill levels and an accurate measure of skill retention post training to reassessment. Our assessment of skill level was carried out at recruitment, however, given the time lag from recruitment to training, objective measures of skill level at both of these timepoints would have been informative.
It wasn't possible to determine which interactions with the RQI training system were for baseline training, reassessment or skills practice. However, study team members carried out baseline and reassessments, supervised training for most participants and recorded the dates and reasons for these contacts. Therefore, a blinded study team member was able to determine the nature of contacts with the system by assuming that contacts outside of scheduled assessments and training were for skills practice.

\subsubsection{Skills practise}

The RQI training system was accessed by $27 \%$ of group C participants outside of scheduled assessment and training timepoints. This was probably to complete training in more than one session, although it is possible that these participants practised skills on these occasions. Group A participants were deactivated on the system post baseline assessment and group $\mathrm{C}$ participants post training, with both reactivated for reassessment. There was an inevitable time lag between remotely deactivating group $\mathrm{C}$ participants post training and re-activating them for their assessment and a period between baseline assessment and training when they were able to access the RQI training system as training sometimes didn't occur until a few months post baseline assessment. Therefore, group $\mathrm{C}$ participants could have practised their compression skills and introduced dilution of effect bias to the study. In addition, the withdrawals predominantly hadn't undertaken their training, so both unofficial skills practice and attrition may have been reduced with training at the point of recruitment.

Participants required prompting to undertake their training, practise their skills (group B only) and complete reassessments. Regular reminders were emailed to participants with pending actions. Indeed, we assumed that group B would want to access the system for skills practise, but they rarely did so.

\subsubsection{Reassessment}

We intended to re-assess groups at three and six-months, but, in practice, there was wide variation in the timepoint at which participants completed their three-month reassessment. Indeed, some reassessments took place up to a year post baseline assessment. This potentially affected the validity of the re-assessment data by introducing confounding factors which may have affected objective comparison. However, this variability was beneficial for the survival analysis because it provided more data points to estimate time to skills degradation. Indeed, only 20 participants were re-assessed twice, therefore, the data from the second reassessment was disregarded. This reflects one of the challenges in conducting a prospective study over an extended timeframe, with 
busy health care workers, and is probably a reason why most published studies report reassessment over a very short timeframe.

\section{Conclusion}

In this pilot, most staff who may need to perform cardiac compressions in hospital were not competent, only $1 / 5$ th were competent at baseline increasing to $1 / 3$ rd post training. Both training and practise increased skill scores suggesting that frequent low-dose training in cardiac compression is required.

Neither training modality was more effective than the other. Technology-enhanced devices, which provide immediate, objective feedback without the need for an instructor to be present, provide an alternate staff training model to instructorfacilitated training. They could improve patient outcomes, allow for higher frequency training and assist hospitals to manage the logistics and cost of providing cardiac compression training. ${ }^{[5]}$ If technology-enhanced training devices are accessible for low dose training 24 hours a day, they are likely to increase competence, confidence and willingness to undertake cardiac compression in clinical situations. ${ }^{[18]}$ However, it is also important to consider other contextual factors, such as drills, and team work, in addition to cardiac compression technique. ${ }^{[32]}$ It would be valuable for future research to determine which training modality is the most cost effective.

The evidence is not sufficiently robust to determine whether increased competence on mannequins translates to higher quality cardiac compression, performed during actual resuscitative attempts, and improved patient outcomes such as return of spontaneous circulation and survival without neurological impairment. ${ }^{[9,29]}$

This pilot trial was valuable in confirming that the approach taken was suitable to test the effects of the intervention and to identify methodological limitations. Sufficient pilot data was generated to test the postulated mechanisms of effect and confirm the feasibility and utility of proposed data collection methods, in preparation for a definitive trial.

\section{FUNDING SUPPORT}

Funding to conduct this study was provided by the Mackay Hospital and Health Service, the Mackay Institute of Research and Innovation and the Mackay Hospital Foundation.

\section{ACKNOWLEDGEMENTS}

We would like to thank the funding bodies and the Health Service staff who participated in this research.

\section{CONFLicts OF INTEREST Disclosure}

The authors declare that there is no conflict of interest.

\section{REFERENCES}

[1] Stiell IG, Brown SP, Christenson J, et al. What is the role of chest compression depth during out-of-hospital cardiac arrest resuscitation? Critical Care Medicine. 2012; 40(4): 1192. PMid:22202708 https://doi.org/10.1097/CCM.0b013e31823bc8bb

[2] Zapletal B, Greif R, Stumpf D, et al. Simulation and education: Comparing three CPR feedback devices and standard BLS in a single rescuer scenario: A randomised simulation study. Resuscitation. 2014; 85: 560-566. PMid:24215730 https ://doi.org/10.1016/ j.resuscitation.2013.10.028

[3] Aguilar SA, Asakawa N, Saffer C, et al. Addition of Audiovisual Feedback During Standard Compressions Is Associated with Improved Ability. Western Journal of Emergency Medicine. 2018; 19(2): 437. PMid:29560078 https://doi .org/10.5811/west jem. 20 17.11 .34327

[4] Cheng A, Brown LL, Duff JP, et al. Improving cardiopulmonary resuscitation with a CPR feedback device and refresher simulations (CPR CARES Study): a randomized clinical trial. JAMA Pediatrics. 2015; 169(2): 137-144. PMid:25531167 https ://doi .org/10.1 001/jamapediatrics. 2014.2616

[5] Johnson M, Peat A, Boyd L, et al. The impact of quantitative feedback on the performance of chest compression by basic life support trained clinical staff. Nurse Education Today. 2016; 45: 163-166. PMid:27522335 https : //doi.org/10.1016/j.nedt. 2016.08 .006

Published by Sciedu Press
[6] Meaney PA, Bobrow BJ, Mancini ME, et al. CPR quality: improving cardiac resuscitation outcomes both inside and outside the hospital: a consensus statement from the American Heart Association. Circulation. 2013.

[7] Hazinski MF, Nolan JP, Aickin R, et al. Part 1: Executive Summary: 2015 International Consensus on Cardiopulmonary Resuscitation and Emergency Cardiovascular Care Science With Treatment Recommendations. Circulation. 2015; 132: S2-S39. PMid:26472854 https ://doi.org/10.1161/CIR.0000000000000270

[8] Talikowska M, Tohira H, Finn J. Cardiopulmonary resuscitation quality and patient survival outcome in cardiac arrest: A systematic review and meta-analysis. Resuscitation. 2015; 96: 66-77. PMid:26247143 https://doi.org/10.1016/j.resuscitatio n.2015.07.036

[9] Kirkbright S, Finn J, Tohira H, et al. Review article: Audiovisual feedback device use by health care professionals during CPR: A systematic review and meta-analysis of randomised and non-randomised trials. Resuscitation. 2014; 85: 460-471. PMid:24361457 https : //doi.org/10.1016/j.resuscitation.2013.12.012

[10] Wallace SK, S AB, B BL. Quantifying the Effect of Cardiopulmonary Resuscitation Quality on Cardiac Arrest Outcome. Circulation: Cardiovascular Quality and Outcomes. 2013; 6(2): 148-156. PMid:23481533 https://doi .org/10.1161/CIRCOUTCOMES 1 11.000041 
[11] Vadeboncoeur T, Stolz U, Panchal A, et al. Clinical Paper: Chest compression depth and survival in out-of-hospital cardiac arrest. Resuscitation. 2014; 85: 182-188. PMid:24125742 https://doi.or g/10.1016/j.resuscitation. 2013.10.002

[12] Stiell IG, Brown SP, Christenson J, et al. What is the role of chest compression depth during out-of-hospital cardiac arrest resuscitation? Critical care medicine. 2012; 40(4): 1192-1198. PMid:22202708 https://doi.org/10.1097/CCM. 0b013e31823bc8bb

[13] Hamilton R. Nurses' knowledge and skill retention following cardiopulmonary resuscitation training: A review of the literature. Journal of Advanced Nursing. 2005; 51(3): 288-297. PMid:16033596 https://doi.org/10.1111/j.1365-2648.2005.03491.x

[14] Buléon C, Parienti JJ, Halbout L, et al. Original Contribution: Improvement in chest compression quality using a feedback device (CPRmeter): a simulation randomized crossover study. American Journal of Emergency Medicine. 2013; 31: 1457-1461. PMid:24035507 https://doi.org/10.1016/j.ajem.2013.07 .029

[15] Baxley SM, Trowbridge C, Cason Carolyn L, et al. A counterbalanced cross-over study of the effects of visual, auditory and no feedback on performance measures in a simulated cardiopulmonary resuscitation. BMC Nursing. 2011; 10(1): 15. PMid:21810239 https://doi.org/10.1186/1472-6955-10-15

[16] Hostler D, Everson-Stewart S, Rea TD, et al. Effect of real-time feedback during cardiopulmonary resuscitation outside hospital: prospective, cluster-randomised trial. BMJ (Clinical Research Ed.). 2011; 342: d512-d512. PMid:21296838 https://doi.org/10.1136/ bmj.d512

[17] Christenson J, Andrusiek D, Everson-Stewart S, et al. Chest Compression Fraction Determines Survival in Patients With Out-ofHospital Ventricular Fibrillation. Circulation. 2009; 120: 1241-1247. PMid:19752324 https://doi.org/10.1161/CIRCULATIONAHA .109 .852202

[18] Greif R, Lockey AS, Conaghan P, et al. European Resuscitation Council Guidelines for Resuscitation 2015. Section 10. Education and implementation of resuscitation. Resuscitation. 2015; 95: 288301. PMid:26477418 https://doi.org/10.1016/j.resuscit ation.2015.07.032

[19] Ackermann AD. Featured Article: Investigation of Learning Outcomes for the Acquisition and Retention of CPR Knowledge and Skills Learned with the Use of High-Fidelity Simulation. Clinical Simulation in Nursing. 2009; 5: e213-e222. https ://doi .org/10 $.1016 / j$. ecns. 2009.05.002

[20] Aqel AA, Ahmad MM. High-Fidelity Simulation Effects on CPR Knowledge, Skills, Acquisition, and Retention in Nursing Students. Worldviews on Evidence-Based Nursing. 2014; 11(6): 394-400. PMid:25213578 https://doi.org/10.1111/wvn.12063

[21] Mpotos N, De Wever B, Cleymans N, Raemaekers J, Valcke M, Monsieurs KG. Simulation and education: Efficiency of short individualised CPR self-learning sessions with automated assessment and feedback. Resuscitation. 2013; 84: 1267-1273. PMid:23511844 ht tps://doi.org/10.1016/j.resuscitation.2013.02.020
[22] Sutton RM, Niles D, Meaney PA, et al. Low-dose, high-frequency CPR training improves skill retention of in-hospital pediatric providers. Pediatrics. 2011; 128(1): e145-e151. PMid:21646262 https://doi.org/10.1542/peds.2010-2105

[23] Bhanji F, Finn JC, Lockey A, et al. Part 8: Education, Implementation, and Teams: 2015 International Consensus on Cardiopulmonary Resuscitation and Emergency Cardiovascular Care Science With Treatment Recommendations. Circulation. 2015; 132: S242. PMid:26472856 https://doi.org/10.1161/CIR. 0000000000 000277

[24] Díez N, Rodríguez-Díez MC, Nagore D, et al. A randomized trial of cardiopulmonary resuscitation training for medical students: voice advisory mannequin compared to guidance provided by an instructor. Simulation in Healthcare. 2013; 8(4): 234-241. PMid:23588058 https://doi .org/10.1097/SIH. 0b013e31828e7196

[25] Kardong-Edgren SE, Oermann MH, Odom-Maryon T, et al. Simulation and education: Comparison of two instructional modalities for nursing student CPR skill acquisition. Resuscitation. 2010; 81: 10191024. PMid:20566391 https://doi.org/10.1016/j.resuscit ation. 2010.04.022

[26] Yeung J, Meeks R, Edelson D, et al. The use of CPR feedback/prompt devices during training and CPR performance: A systematic review. Resuscitation. 2009; 80(7): 743-751. PMid:19477574 https : //doi.org/10.1016/j.resuscitation. 2009.04.012

[27] Mundell WC, Kennedy CC, Szostek JH, Cook DA. Simulation technology for resuscitation training: a systematic review and metaanalysis. Resuscitation. 2013; 84(9): 1174-1183. PMid:23624247 ht tps://doi.org/10.1016/j.resuscitation. 2013.04.016 v

[28] Sutton RM, Niles D, Meaney PA, et al. "Booster" training: evaluation of instructor-led bedside cardiopulmonary resuscitation skill training and automated corrective feedback to improve cardiopulmonary resuscitation compliance of Pediatric Basic Life Support providers during simulated cardiac arrest. Pediatric Critical Care Medicine: a journal of the Society of Critical Care Medicine and the World Federation of Pediatric Intensive and Critical Care Societies. 2011; 12(3): e116. PMid:20625336 https://doi.org/10.1097/PCC.0b013e $3181 \mathrm{e} 91271$

[29] Yeung J, Meeks R, Edelson D, et al. Review: The use of CPR feedback/prompt devices during training and CPR performance: A systematic review. Resuscitation. 2009; 80: 743-751. PMid:19477574 https://doi.org/10.1016/j.resuscitatio n. 2009.04.012

[30] Gonzi G, Sestigiani F, D'Errico A, et al. Correlation between quality of cardiopulmonary resuscitation and self-efficacy measured during in-hospital cardiac arrest simulation; preliminary results. Acta Bio-Medica: Atenei Parmensis. 2015; 86 Suppl 1: 40-45.

[31] Kaye W, Wynne G, Marteau T, et al. An advanced resuscitation training course for preregistration house officers. Journal of the Royal College of Physicians of London. 1990; 24(1): 51-54.

[32] Sullivan NJ, Duval-Arnould J, Twilley M, et al. Simulation and education: Simulation exercise to improve retention of cardiopulmonary resuscitation priorities for in-hospital cardiac arrests: A randomized controlled trial. Resuscitation. 2015; 86: 6-13. PMid:25447038 ht tps://doi.org/10.1016/j.resuscitation.2014.10.021 